\title{
Epidemiology of dyslipidemia in Chinese adults: meta-analysis of prevalence, awareness, treatment, and control
}

\author{
Yuanxiu Huang ${ }^{1}$, Lin Gao ${ }^{1}$, Xiaoping Xie $^{2}$ and Seng Chuen Tan ${ }^{3^{*}}$
}

\begin{abstract}
Background: Numerous epidemiology studies on dyslipidemia have been conducted in China. However, a nationally representative estimate for dyslipidemia prevalence is lacking. The aim of this study is to appraise the nationwide prevalence, awareness, treatment, and control rates of dyslipidemia in adults in China.

Methods: We performed a systematic review of the related observational studies published since 2003 by searching English and Chinese literature databases. Meta-analyses were conducted in eligible studies using a random effect model to summarize the dyslipidemia prevalence, awareness, treatment, and control rates. Heterogeneity and publication bias were analyzed. Sensitivity analyses were performed to explain heterogeneity and examine the impact of study quality on the results of meta-analyses.

Results: Thirty-eight papers were included for meta-analyses, with a total sample size of 387,825. The prevalence, awareness, treatment, and control rates of dyslipidemia were $41.9 \%$ (95\% Cl: $37.7 \%-46.2 \%), 24.4 \%$ (95\% Cl: 14.4\% - 38.4\%), $8.8 \%$ (95\% Cl: 7.7\% - 10.0\%), and 4.3\% (95\% Cl: $4.1 \%-4.5 \%)$, respectively. The prevalence of hypercholesterolemia, hypertriglyceridemia, mixed hyperlipidemia, low levels of high-density lipoprotein cholesterol, and high levels of low-density lipoprotein cholesterol were 10.1\% (95\% Cl: 5.8\% - 16.9\%), 17.7\% (95\% Cl: $14.0 \%$ - 22.1\%), 5.1\% (95\% Cl: 3.1\% - 8.2\%), $11.0 \%$ (95\% Cl: 8.0\% - 15.0\%), and 8.8\% (95\% Cl: 4.1\% - 17.8\%), respectively. Sensitivity analyses revealed that males had a higher prevalence of dyslipidemia (43.2\%) than females (35.6\%). Study samples of age 30 and above in the eastern region tended to have higher prevalence of dyslipidemia. The quality of the studies has a slight impact on the pooled estimates.

Conclusions: The overall pooled prevalence of dyslipidemia in Chinese adults was estimated to be $41.9 \%$, with males having a higher rate than females.
\end{abstract}

Keywords: Dyslipidemia, Prevalence, Awareness rate, Treatment rate, Control rate, Meta-analysis

\section{Introduction}

Dyslipidemia represents one of the major risk factors for atherosclerosis affecting arteries of large and medium size and consequently causing ischemia in the brain, heart, or legs. Coronary artery disease and cerebral stroke represent the major causes of morbidity and mortality among elderly and middle aged subjects [1]. The prevalence of dyslipidemia has increased dramatically in Chinese cities with lifestyle changes over the past decade, and cardiovascular

\footnotetext{
* Correspondence: sctan@sg.imshealth.com

${ }^{3}$ Health Economics \& Outcomes Research, IMS Health Asia Pacific, 8 Cross Street, \#21-01/02/03 PWC Building, Singapore 048424, Singapore
} Full list of author information is available at the end of the article diseases have emerged as a leading cause of death in Chinese adults [2].

Surveys investigating the epidemiological data of dyslipidemia in Chinese adults have been published, but the results vary due to diverse populations of different regions and the use of different diagnosis criteria [2]. An overall appraisal of dyslipidemia epidemiology nationwide in China would potentially benefit future research and policy discussions. We therefore performed metaanalyses by a comprehensive systematic review of all available evidence to synthesize the current dyslipidemia prevalence, awareness, treatment, and control among Chinese adults. 


\section{Methods}

\section{Search strategy and eligibility criteria}

Based on the MOOSE guideline [3], we identified epidemiological studies on dyslipidemia in Chinese adults published in English or Chinese between January 2003 and August 2013. The search strategy comprised of a search of Western electronic databases (including Medline, Embase, and CINAHL) and a search of Chinese databases (including SinoMed, CNKI, and Wanfang Data). We used the search terms "dyslipidemia", "hyperlipidemia", "epidemiology", "incidence", "prevalence", "awareness rate", "treatment rate", "control rate", "China or Chinese", and these terms' variants and combinations.

Eligible studies had to have reported any of the following epidemiological data related to dyslipidemia in sampled populations of Chinese subjects: prevalence, awareness rate, treatment rate, and control rate. The diagnosis criteria was based on the Chinese Guidelines on Prevention and Treatment of Dyslipidemia in Adults [2], which defined dyslipidemia as any one of the following four conditions: hypercholesterolemia (total cholesterol $(\mathrm{TC}) \geq 6.22 \mathrm{mmol} / \mathrm{L}$ ); hypertriglyceridemia (triglycerides $(\mathrm{TG}) \geq 2.26 \mathrm{mmol} / \mathrm{L}$ ); low levels of high-density lipoprotein cholesterol (HDL-C < $1.04 \mathrm{mmol} / \mathrm{L}$ ); high levels of low-density lipoprotein cholesterol (LDL-C $\geq 4.14 \mathrm{mmol} / \mathrm{L}$ ).

Dyslipidemia awareness was defined as a self-report of any prior laboratory diagnosis of dyslipidemia. Treatment was defined broadly as interventions including medication, diet, exercise, and monitoring to manage dyslipidemia. Participants were considered to have controlled dyslipidemia if their serum TC, TG, LDL-C, and HDL-C were within the normal ranges as defined above based on the 2007 Chinese guidelines.

We also applied the following exclusion criteria in filtering the identified publications:

- Non-human studies

- Non-research based publications such as press releases, newsletters, forum discussions, etc.

- Non-epidemiological studies such as basic science research on dyslipidemia.

- Studies that did not disclose when the data was collected, sample size, or denominator for each reported prevalence or rate.

- Studies that investigated specific populations such as military, prisoners, specific ethnic groups, etc.

- Studies that did not apply the diagnosis criteria published in the 2007 Chinese Guidelines on Prevention and Treatment of Dyslipidemia in Adults.

\section{Study identification and data extraction}

We identified relevant studies by searching electronic databases, scanning reference lists, and consulting clinical experts in dyslipidemia. Additionally, studies presented at key conference proceedings were identified. Two reviewers independently examined all the titles and abstracts of the studies retrieved from the searches for potentially eligible studies, then the full text of all potentially relevant citations were obtained and independently assessed by the reviewers to confirm whether they met the inclusion criteria. The results were checked and discussed by the two reviewers to agree upon a final list of included studies.

Using a standardized and predesigned data collection form, all relevant data in each included paper were extracted by two reviewers independently. The data extracted were cross-checked and any unresolved discrepancies were referred to a third reviewer. Where necessary, inputs of a clinical expert advisor were solicited to facilitate discussions among the reviewers.

For each included study, we extracted general information (including authors, year, title, type of publication, etc.), study characteristics (including study design, population, location, diagnosis criteria, sample size, etc.), participants' characteristics (including age, sex, type of dyslipidemia, etc.). We further recorded the numbers of people with any one type of dyslipidemia condition and reported awareness, treatment, and control rates. The data stratified by sex and dyslipidemia types, where available, were also extracted.

To inform the appropriateness of included studies in the meta-analysis and later evaluate the strength of the evidence, the two reviewers independently assessed and agreed on the quality of each included study using the quality assessment checklist for epidemiological studies [4]. The checklist assesses the quality of studies on a scale of 0 (the worst) to 18 (the best) using predefined criteria on both internal and external validities [4].

\section{Statistical analyses and heterogeneity test}

Pooled estimates of the dyslipidemia prevalence, awareness rate, treatment rate, and control rate and their corresponding 95\% confidence intervals (CI) were calculated based on the random effect model [5] and stratified by sex and age group (over 18 or over 30 years) where applicable. Heterogeneity between studies was evaluated with the Cochran's Q test and $\mathrm{I}^{2}$ statistic, which describes the percentage of variation across studies (values of $25 \%, 50 \%$, and $75 \%$ indicate low, moderate, and high degrees of heterogeneity, respectively) [6,7]. Subgroup analyses were performed to investigate potential sources of heterogeneity from different geographical regions and types of dyslipidemia. Publication bias was evaluated by using the funnel plots method. Furthermore, sensitivity analyses were performed to evaluate the influence of particular study on a pooled estimate, which was recalculated by omitting a study each time. Independent or paired t-tests were used as appropriate, and a significant difference was reported if 
the p-value was less than 0.05. All statistical analyses were performed using SPSS version 20.0 (SPSS Inc, Chicago, USA) and Comprehensive Meta-Analysis software version 2.0 (Biostat, Englewood, USA).

\section{Results}

\section{Characteristics of included studies}

Our searches retrieved 7669 citations. Of these, 6800 were excluded after reading the abstracts, and 831 were further excluded after assessing the full papers, leaving 38 eligible papers for inclusion in our review and analyses (Figure 1) [8-45], which involved a total of 387,825 Chinese people.

Among the 38 included papers, 36 were written in Chinese and two were written in English; 33 studies were cross-sectional surveys and five studies employed census surveys or other designs; 18 studies were conducted in eastern China, 10 studies were conducted in central China, eight studies were conducted in western China, and two surveys crossed regions nationwide (Table 1) [8-45].

Study quality was assessed for the 38 included papers. Four papers had quality scores between eight and 10 points, 13 papers had scores between 11 and 13 points, and 21 papers had scores between 14 and 16 points. Overall study quality was upper-middle and high, and the study quality did not differ significantly among the included studies.

\section{Prevalence of dyslipidemia}

Twenty-eight papers reported the total numbers of participants in the studies and those who were diagnosed with dyslipidemia (Figure 2). The pooled prevalence of dyslipidemia in Chinese adults was $41.9 \%$ (95\% CI: $37.7 \%-46.2 \%)$. The t-tests showed there were no statistically significant differences between subgroups stratified by age and geographic region (Tables 2 and 3); however, the pooled prevalence of dyslipidemia in males (43.2\%) was higher than in female (35.6\%) with statistical significance $(t=3.08, \mathrm{p}<0.05)$.

In terms of the different types of dyslipidemia, the pooled prevalence estimates of hypercholesterolemia (TC), hypertriglyceridemia (TG), mixed hyperlipidemia (TC + TG), low levels of high-density lipoprotein cholesterol (HDL-C), and high levels of low-density lipoprotein cholesterol (LDL-C) are 10.1\% (95\% CI: 5.8\% - 16.9\%), 17.7\% (95\% CI: $14.0 \%$ - 22.1\%), 5.1\% (95\% CI: $3.1 \%-$ $8.2 \%), 11.0 \%$ (95\% CI: $8.0 \%-15.0 \%$ ), and $8.8 \%$ (95\% CI: $54.1 \%-17.8 \%)$, respectively. There were no significant differences between age groups within each type of dyslipidemia condition (Table 4 and Additional file 1).

\section{Dyslipidemia awareness, treatment, and control}

Using the dyslipidemia awareness rates reported in four studies, we arrived at a pooled estimate of $24.4 \%$ (95\% CI: $14.4 \%-38.4 \%)$. Based on the reported dyslipidemia treatment rates in two studies, we estimated a pooled treatment rate of $8.8 \%$ (95\% CI: $7.7 \%-10.0 \%$ ). There were no significant differences between males and females in terms of dyslipidemia awareness and treatment rates (Table 5). Only one paper reported a dyslipidemia control rate, which was $4.3 \%$ (3.1\% for males and 5.5\% for females).

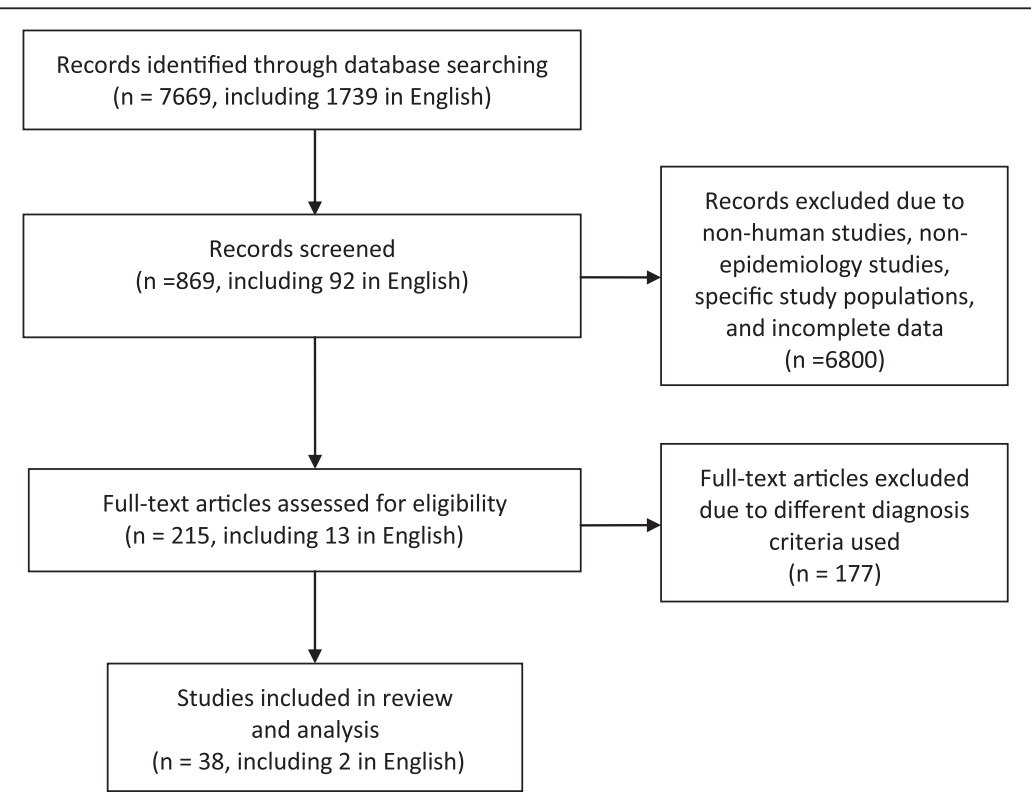

Figure 1 Flow chart of screening and inclusion of studies for review and analysis. 
Table 1 Characteristics of included studies

\begin{tabular}{|c|c|c|c|c|c|c|}
\hline Author & Year & Region & Age range & Number of participants & $\begin{array}{l}\text { Number of patients diagnosed } \\
\text { with dyslipidemia }\end{array}$ & $\begin{array}{l}\text { Score of quality } \\
\text { assessment }\end{array}$ \\
\hline Luo $R$ & 2009 & Chongqing & $18-59 y$ & 20000 & 6464 & 12 \\
\hline Guo MH & 2011 & Beijing & $18-79 y$ & 6790 & 3231 & 10 \\
\hline $\operatorname{Li} Y$ & 2008 & Beijing & $18-79 y$ & 2776 & 1269 & 15 \\
\hline Luo WP & 2010-2011 & Xinjiang & $\geq 18 y$ & 2999 & 2277 & 14 \\
\hline You AG & $2007-2008$ & Henan & $\geq 18 y$ & 20194 & - & 15 \\
\hline $\mathrm{Li} \mathrm{JH}$ & 2010 & National & $\geq 18 y$ & 97409 & - & 15 \\
\hline Mo J & 2010 & Guangdong & $\geq 18 y$ & 3577 & 2173 & 16 \\
\hline Pang QY & 2006 & Henan & $\geq 18 y$ & 984 & 314 & 9 \\
\hline Pang QY & 2007 & Henan & $\geq 18 y$ & 10127 & 4392 & 11 \\
\hline $\mathrm{Li} \mathrm{JH}$ & 2010 & National & $\geq 18 y$ & 97409 & 51818 & 15 \\
\hline Chen YY & 2010 & Jiangxi & $\geq 18 y$ & 3000 & 1821 & 14 \\
\hline Zhang XW & 2010 & Zhejiang & $\geq 18 y$ & 17437 & 8694 & 14 \\
\hline $\mathrm{Li} \mathrm{XH}$ & $2007-2008$ & Gansu & $>18 y$ & 3038 & 793 & 14 \\
\hline $\mathrm{Hu} X \mathrm{~L}$ & - & Zhejiang & $>18 y$ & 2036 & - & 12 \\
\hline Li SL & $2007-2008$ & Shanxi & $20-74$ y & 1286 & 459 & 14 \\
\hline Gao B & $2007-2008$ & Shanxi & $20-74 y$ & 3298 & 1106 & 15 \\
\hline Jin LZ & 2007 & Guangdong & $20-74$ y & 1134 & - & 12 \\
\hline Li J & 2009 & Beijing & $20-78$ y & 4332 & 1008 & 13 \\
\hline Wang JH & 2007 & Beijing & $\geq 20 y$ & 10054 & - & 13 \\
\hline Fu YY & 2007 & Beijing & $\geq 20 y$ & 10054 & 3373 & 16 \\
\hline Yin L & $2008-2009$ & Hunan & $>20 y$ & 1544 & 695 & 8 \\
\hline Fu YY & 2007 & Beijing & $>20 y$ & 9786 & 3347 & 14 \\
\hline Guang ZJ & 2011 & Beijing & $21-91$ y & 3340 & 993 & 14 \\
\hline Liu XY & 2008 & Ningxia & $\geq 25 y$ & 1275 & 619 & 14 \\
\hline Yuan XH & - & Guangdong & $>30 y$ & 1053 & 465 & 8 \\
\hline Liao XY & 2010 & Sichuan & $35-70$ y & 2032 & 474 & 14 \\
\hline Wang CJ & - & Henan & $35-78$ y & 16926 & 7480 & 14 \\
\hline Shao YQ & 2008 & Zhejiang & $>35 y$ & 7194 & - & 15 \\
\hline Zhou WJ & $2008-2009$ & Jiangsu & $>35 y$ & 2102 & 922 & 14 \\
\hline Li J & 2009 & Shandong & $>35 y$ & 1972 & - & 15 \\
\hline $\mathrm{LiY}$ & 2008 & Hubei & $>35 y$ & 9865 & 2794 & 16 \\
\hline Gao Y & 2011 & Jilin & $40-70 y$ & 1332 & 618 & 12 \\
\hline Liu DW & - & Henan & $\geq 45 y$ & 4779 & - & 12 \\
\hline Zhao YZ & - & Sichuan & $>45 y$ & 200 & 113 & 11 \\
\hline Wu ZF & $2007-2008$ & Tianjin & $50-94$ y & 1424 & - & 11 \\
\hline Sheng $L$ & 2009 & Beijing & $>60 y$ & 2685 & - & 13 \\
\hline $\mathrm{Hu} X Z$ & 2007 & Henan & $>60 y$ & 1247 & 347 & 13 \\
\hline Liang YQ & 2011 & Guangdong & $>60 y$ & 1135 & 680 & 12 \\
\hline
\end{tabular}

\section{Sensitivity analysis, publication bias and heterogeneity} Two studies were assessed with a quality score of eight, the lowest among the included studies. In the sensitivity analysis, omitting these two studies resulted in a slight change in the pooled dyslipidemia prevalence estimate,
41.7\% from $41.9 \%$. The pooled prevalence of TC, TG, HDL-C, and LDL-C changed to $9.4 \%, 17.0 \%, 10.7 \%$, and $8.3 \%$ from $10.1 \%, 17.7 \%, 11.0 \%$, and $8.8 \%$, respectively. Funnel plots were produced for the prevalence of each type of dyslipidemia (see the Additional file 1). Asymmetric funnels 


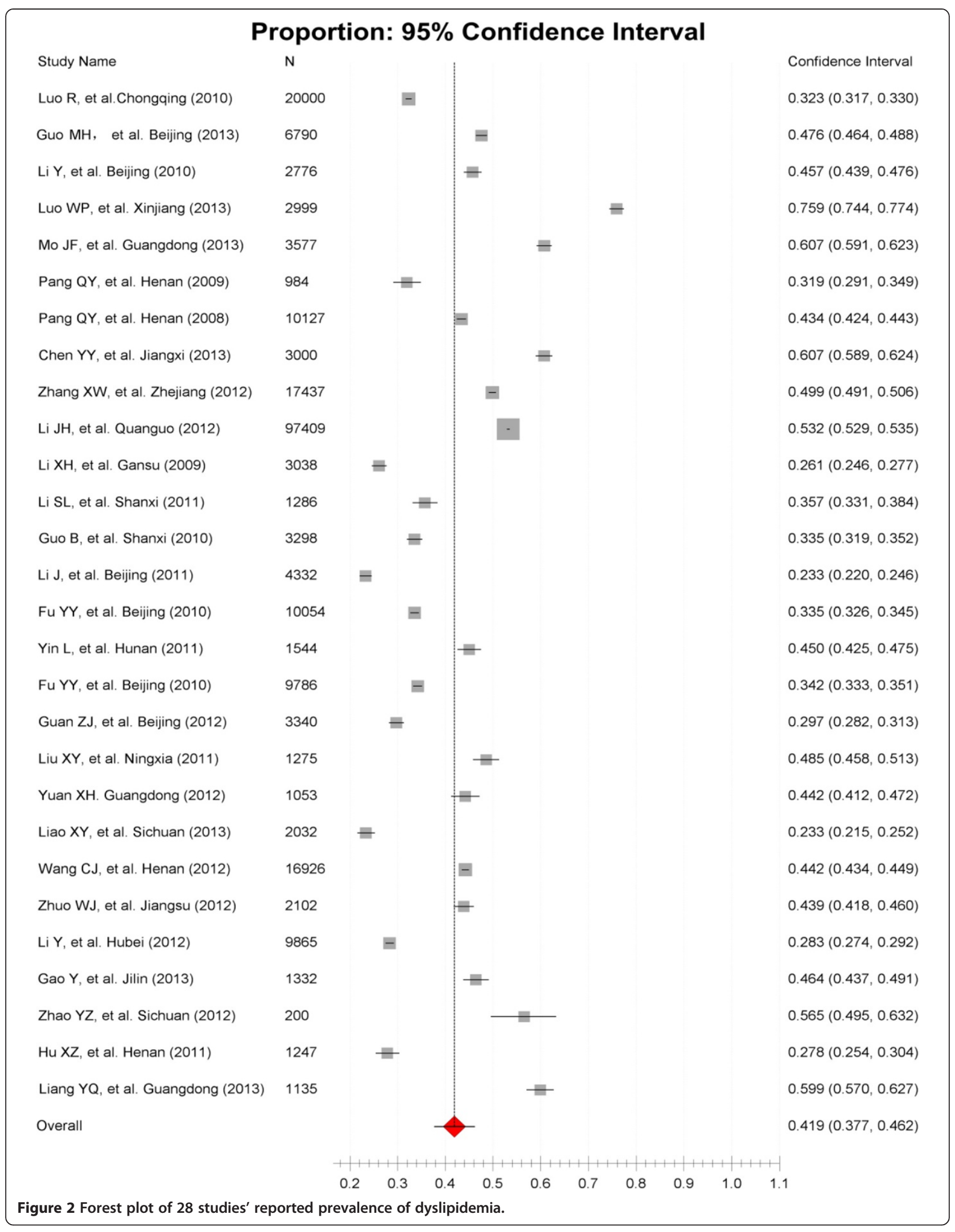


Table 2 Prevelance of dyslipidemia by different age groups

\begin{tabular}{|c|c|c|c|c|c|c|}
\hline Age range & Number of studies & $\begin{array}{l}\text { Total numbers } \\
\text { of participants }\end{array}$ & Median (\%) & Minimum (\%) & Maximum (\%) & $\begin{array}{l}\text { Pooled prevalence } \\
(\%)(95 \% \mathrm{Cl})\end{array}$ \\
\hline$\geq 18 y$ & 19 & 203052 & 43.4 & 23.3 & 75.9 & $42.4(37.2 \sim 47.7)$ \\
\hline$\geq 30 y$ & 9 & 35892 & 44.2 & 23.3 & 59.9 & $40.9(33.7 \sim 48.5)$ \\
\hline Total & 28 & 238944 & 44 & 23.3 & 75.9 & $41.9(37.7 \sim 46.2)$ \\
\hline
\end{tabular}

suggest the possibility of publication bias. A moderate degree of heterogeneity was observed in the pooled dyslipidemia prevalence $\left(\mathrm{I}^{2}=49.9 \%, \mathrm{Q}=1.00, \mathrm{P}<0.001\right)$, awareness rate $\left(\mathrm{I}^{2}=49.9 \%, \mathrm{Q}=0.99, \mathrm{P}<0.001\right)$, and treatment rate $\left(\mathrm{I}^{2}=38.0 \%, \mathrm{Q}=0.721, \mathrm{P}=0.098\right)$.

\section{Discussion}

Our systematic review included 38 observational studies conducted in the past decade, covering most of the regions in China, and involving a total of 387,825 participants, representing the adult Chinese population. The pooled estimates from the meta-analyses showed high prevalence of dyslipidemia and low awareness, treatment, and control rates. The study and results are timely, as currently there is a lack of published up-todate nationwide epidemiological data of dyslipidemia to support the evidence-based approach and management of dyslipidemia in China.

The pooled estimate of dyslipidemia prevalence among Chinese adults is $41.9 \%$, which has more than doubled in the last 10 years [46], approaching the reported prevalence of $53 \%$ from the US National Health and Nutrition Examination Survey 2003-2006 [47]. The observed increase of dyslipidemia prevalence in China could possibly be attributed to the increasingly aging population and dramatic lifestyle changes coupled with economic growth, especially changes in cigarette smoking, dietary, and alcohol drinking behaviors among the general population [48].

The study discovered that hypertriglyceridemia (TG) was the most prevalent form of dyslipidemia, with a pooled estimate of $17.7 \%$, followed by low levels of blood high-density lipoprotein cholesterol (HDL-C) (11.0\%), hypercholesterolemia (TC) (10.1\%), high levels of lowdensity lipoprotein cholesterol (LDL-C) (8.8\%), and mixed hyperlipidemia (TC+TG) (5.1\%). As dyslipidemia is one of the well-established risk factors for cardiovascular diseases [47], these results highlight the extensive need for appropriate interventions, both clinical and non-clinical, to treat all types of dyslipidemia. In addition, other considerations such as improving general awareness about dyslipidemia among

Table 3 Prevalence of dyslipidemia by different regions and sexes

\begin{tabular}{|c|c|c|c|c|c|c|c|}
\hline \multicolumn{2}{|l|}{ Groups } & Number of studies & $\begin{array}{l}\text { Total number } \\
\text { of participants }\end{array}$ & Median (\%) & Minimum (\%) & Maximum (\%) & $\begin{array}{l}\text { Pooled prevalence } \\
(\%)(95 \% \mathrm{Cl})\end{array}$ \\
\hline \multicolumn{8}{|l|}{$\geq 18 y$} \\
\hline \multirow[t]{2}{*}{ Sex } & Male & 15 & 80145 & 44.3 & 25.8 & 68.9 & $45.6(40.0 \sim 51.4)$ \\
\hline & Female & 15 & 96864 & 33.7 & 14.6 & 56.4 & $35.9(29.5 \sim 42.8)$ \\
\hline \multirow[t]{3}{*}{ Region } & Eastern China & 8 & 58092 & 40 & 23.3 & 60.7 & $40.0(32.6 \sim 47.9)$ \\
\hline & Central China & 4 & 15655 & 44.2 & 31.9 & 60.7 & $45.1(35.2 \sim 55.5)$ \\
\hline & Western China & 6 & 31896 & 34.6 & 26.1 & 75.9 & $41.9(28.9 \sim 56.1)$ \\
\hline \multicolumn{8}{|l|}{$\geq 30 y$} \\
\hline \multirow[t]{2}{*}{ Sex } & Male & 3 & 5442 & 26.2 & 24.9 & 45.3 & $31.5(20.7 \sim 44.8)$ \\
\hline & Female & 3 & 7772 & 30.2 & 29.9 & 43 & $34.1(26.1 \sim 43.3)$ \\
\hline \multirow[t]{3}{*}{ Region } & Eastern China & 3 & 4290 & 44.2 & 43.9 & 59.9 & $49.3(39.4 \sim 59.3)$ \\
\hline & Central China & 4 & 29370 & 36.3 & 27.8 & 46.4 & $36.3(26.6 \sim 47.1)$ \\
\hline & Western China & 2 & 2232 & 39.9 & 23.3 & 56.5 & $38.5(13.1 \sim 72.2)$ \\
\hline \multicolumn{8}{|l|}{ Total } \\
\hline \multirow[t]{2}{*}{ Sex } & Male & 18 & 85587 & 43.7 & 24.9 & 68.9 & $43.2(37.4 \sim 49.1)$ \\
\hline & Female & 18 & 104636 & 32.7 & 14.6 & 56.4 & $35.6(30.0 \sim 41.7)$ \\
\hline \multirow[t]{3}{*}{ Region } & Eastern China & 11 & 62382 & 44.2 & 23.3 & 60.7 & $42.5(36.1 \sim 49.2)$ \\
\hline & Central China & 8 & 45025 & 43.8 & 27.8 & 60.7 & $40.6(33.9 \sim 47.7)$ \\
\hline & Western China & 8 & 34128 & 34.6 & 23.3 & 75.9 & $41.0(30.0 \sim 53.0)$ \\
\hline
\end{tabular}


Table 4 Prevelance of dyslipidemia by different dyslipidemia types

\begin{tabular}{|c|c|c|c|c|c|c|c|}
\hline Types & $\begin{array}{l}\text { Age } \\
\text { group }\end{array}$ & $\begin{array}{l}\text { Number of } \\
\text { studies }\end{array}$ & $\begin{array}{l}\text { Total number of } \\
\text { participants }\end{array}$ & Median (\%) & Minimum (\%) & Maximum (\%) & $\begin{array}{l}\text { Pooled prevalence } \\
(\%)(95 \% \mathrm{Cl})\end{array}$ \\
\hline \multirow[t]{3}{*}{ Hypercholesterolemia (TC) } & $\geq 18 y$ & 9 & 143350 & 7.7 & 2.5 & 41.8 & $7.9(4.6 \sim 13.2)$ \\
\hline & $\geq 30 y$ & 10 & 41366 & 10.8 & 4.9 & 48.1 & $12.5(5.8 \sim 25.0)$ \\
\hline & Total & 19 & 184716 & 8.2 & 2.5 & 48.1 & $10.1(5.8 \sim 16.9)$ \\
\hline \multirow[t]{3}{*}{ Hypertriglyceridemia (TG) } & $\geq 18 y$ & 9 & 143350 & 15.3 & 4.5 & 36.9 & $13.7(10.7 \sim 17.4)$ \\
\hline & $\geq 30 y$ & 10 & 41367 & 18.8 & 11.7 & 44.5 & $22.1(16.0 \sim 29.7)$ \\
\hline & Total & 19 & 184717 & 17.1 & 4.5 & 44.5 & $17.7(14.0 \sim 22.1)$ \\
\hline \multirow[t]{3}{*}{ Mixed hyperlipidemia (TC + TG) } & $\geq 18 y$ & 3 & 11249 & 6.5 & 1.9 & 4.2 & $4.8(2.4 \sim 9.2)$ \\
\hline & $\geq 30 y$ & 1 & 2102 & - & - & - & - \\
\hline & Total & 4 & 13351 & 6.4 & 1.9 & 8.3 & $5.1(3.1 \sim 8.2)$ \\
\hline \multirow{3}{*}{$\begin{array}{l}\text { Low blood high-density lipoprotein } \\
\text { cholesterol (HDL-C) }\end{array}$} & $\geq 18 y$ & 9 & 143350 & 6.9 & 0.2 & 57.3 & $11.0(6.9 \sim 16.9)$ \\
\hline & $\geq 30 y$ & 9 & 38129 & 10.1 & 1.6 & 32.8 & $11.0(6.6 \sim 17.9)$ \\
\hline & Total & 18 & 181479 & 10 & 0.2 & 57.3 & $11.0(8.0 \sim 15.0)$ \\
\hline \multirow{3}{*}{$\begin{array}{l}\text { High blood low-density lipoprotein } \\
\text { cholesterol (LDL-C) }\end{array}$} & $\geq 18 y$ & 5 & 130826 & 3.1 & 2.3 & 67.5 & $7.6(2.1 \sim 24.3)$ \\
\hline & $\geq 30 y$ & 7 & 29843 & 12.2 & 1.7 & 21.3 & $9.7(4.5 \sim 19.8)$ \\
\hline & Total & 12 & 160669 & 8.8 & 1.7 & 67.5 & $8.8(4.1 \sim 17.8)$ \\
\hline
\end{tabular}

both patients and health care professionals and promoting healthy diet and lifestyles are equally important in designing and implementing relevant public health strategies.

We calculated and compared the pooled estimates of dyslipidemia prevalence in age groups over 18 years and over 30 years. No significant difference was found between these age groups across different types of dyslipidemia conditions. However, trends of higher prevalence of TC, TG, and LDL-C abnormalities were observed in studies of older participants ( $\geq 30$ years old) compared to those studies that enrolled younger participants ( $\geq 18$ years old). We observed the highest estimate at 49.3\% (95\% CI: 39.4-59.3) among all of the pooled prevalence estimates in people over 30 years old in the eastern region of China. Another study in China concluded that greater burden of diet-related chronic conditions including dyslipidemia has been observed in economically vibrant and highly urbanized areas [49], which are predominantly in the eastern coastal region. More economically developed areas tend to have better access to health care facilities, which might have contributed to diagnosis and hence higher reported prevalence rates in these studies among populations in the eastern region of China.

The systematic review showed that dyslipidemia is more common in men than in women, which is consistent with the findings from American population-based studies [50,51]. There were no significant differences in awareness, treatment, and control rates between the groups of men and women in China. However, studies conducted in the US showed that dyslipidemia was treated and controlled less often in men than in women [50]. A possible explanation for the higher dyslipidemia prevalence observed in men could be their higher probability of cigarette smoking, alcohol, and consumption of foods high in cholesterol.

Table 5 Dyslipidemia awareness and treatment rates

\begin{tabular}{|c|c|c|c|c|c|c|}
\hline Groups & Number of studies & $\begin{array}{l}\text { Total number } \\
\text { of participants }\end{array}$ & Median (\%) & Minimum (\%) & Maximum (\%) & $\begin{array}{l}\text { Pooled prevalence } \\
(\%)(95 \% \mathrm{Cl})\end{array}$ \\
\hline \multicolumn{7}{|c|}{ Awareness rate } \\
\hline Male & 3 & 28021 & 25 & 12.4 & 25.3 & $20.1(11.2 \sim 33.3)$ \\
\hline Female & 3 & 28439 & 31.2 & 14.7 & 32.9 & $25.2(13.0 \sim 43.1)$ \\
\hline Total & 4 & 59807 & 28.9 & 13.5 & 29.8 & $24.4(14.4 \sim 38.4)$ \\
\hline \multicolumn{7}{|c|}{ Treatment rate } \\
\hline Male & 2 & 26620 & 7.2 & 6.8 & 7.6 & $7.6(7.3 \sim 7.9)$ \\
\hline Female & 2 & 26467 & 10.9 & 9.2 & 12.5 & $10.6(7.8 \sim 14.2)$ \\
\hline Total & 2 & 53087 & 9.1 & 8.4 & 9.7 & $8.8(7.7 \sim 10.0)$ \\
\hline
\end{tabular}


The quality of studies included in our systematic review were generally good, thus the sensitivity analysis did not demonstrate much difference in the results of meta-analyses when the studies with the lowest quality scores were removed in the analyses. We believe our searches were comprehensive, although the asymmetric funnel plots suggested the possibility of publication bias. The moderate heterogeneity observed could come from the different study settings and populations. We investigated possible sources and performed subgroup analyses, but that still inadequately explained the heterogeneity findings in this study. The recent research of heterogeneity suggested that $\mathrm{I}^{2}$ estimates need to be interpreted with caution when a meta-analysis only includes a limited number of events or trials, in particular when the number of studies for further subgroup analyses is small [52]. Nevertheless, these uncertainties indicate the need of a higher-quality national survey with larger samples with better represented coverage across China.

Our study has some limitations. First, all the included studies were published after 2007 as we used the Chinese Guidelines on Prevention and Treatment of Dyslipidemia in Adults, published in 2007, as the diagnosis criteria [2]. Studies published before 2007 were based on a different set of diagnosis criteria, and therefore have not been included in our meta-analyses. Secondly, we could not investigate the differences in dyslipidemia prevalence between rural and urban areas due to the limited information reported in the included studies. Furthermore, we would like to highlight that the meta-analysis results on awareness, treatment, and control rate need to be interpreted with caution, as the number of studies reporting the relevant data are relatively small.

\section{Conclusions}

The pooled estimate of dyslipidemia prevalence among Chinese adults was $41.9 \%$, and hypertriglyceridemia (TG) is the most prevalent dislipidemia condition. The prevalence of dyslipidemia in males was higher than in females. Our study also showed low dyslipidemia awareness, treatment, and control rates in China.

\section{Additional file}

Additional file 1: Forest plots and funnel plots of different sets of analyses are available as appendices at PHM online.

\section{Competing interests}

$X$. Xie is currently employed as a researcher in health outcomes by Pfizer Investment Co. Ltd., at Beijing. The other authors declare that they have no competing interests.

\section{Authors' contributions}

$Y H, L G$, and XX developed the study objective and scope, search strategy, and conducted the literature search, selection of included studies, and endpoints. YH and LG completed data extraction and statistical analyses. XX and SCT reviewed the analyses and contributed to the discussion of the study. The manuscript was drafted, reviewed, and agreed by all co-authors. All authors approved the final version of the manuscript.

\section{Funding}

This study has been funded by Pfizer Investment Co. Ltd., Beijing, China, including all costs associated with the development and the publishing of the present manuscript. Funding was not contingent upon publication of the manuscript.

\section{Author details}

${ }^{1}$ School of Public Health, Central South University, Changsha, China. ${ }^{2}$ Outcomes Research, Pfizer Investment Co. Ltd, Beijing, China. ${ }^{3}$ Health Economics \& Outcomes Research, IMS Health Asia Pacific, 8 Cross Street, \#21-01/02/03 PWC Building, Singapore 048424, Singapore.

Received: 12 March 2014 Accepted: 1 October 2014

Published online: 28 October 2014

\section{References}

1. Pisciotta L, Bertolini S, Pende A: Lipoproteins, stroke and statins. Curr Vasc Pharmacol 2013, [Epub ahead of print].

2. Joint Committee for Developing Chinese guidelines on Prevention and Treatment of Dyslipidemia in Adults: Chinese guidelines on prevention and treatment of dyslipidemia in adults. Zhonghua Xin Xue Guan Bing Za Zhi 2007, 35(5):390-419.

3. Stroup DF, Berlin JA, Morton SC, Olkin I, Williamson GD, Rennie D, Moher D, Becker BJ, Sipe TA, Thacker SB: Meta-analysis of observational studies in epidemiology: a proposal for reporting. Meta-analysis Of Observational Studies in Epidemiology (MOOSE) group. JAMA 2000, 283(15):2008-2012.

4. Prins J, Blanker MH, Bohnen AM, Thomas S, Bosch JL: Prevalence of erectile dysfunction: a systematic review of population-based studies. Int I Impot Res 2002, 14(6):422-432.

5. Schmidt FL, Oh IS, Hayes TL: Fixed- versus random-effects models in meta-analysis: model properties and an empirical comparison of differences in results. Br J Math Stat Psychol 2009, 62(Pt 1):97-128.

6. Huedo-Medina TB, Sanchez-Meca J, Marin-Martinez F, Botella J: Assessing heterogeneity in meta-analysis: $\mathrm{Q}$ statistic or 12 index? Psychol Methods 2006, 11(2):193-206.

7. Higgins JP, Thompson SG, Deeks JJ, Altman DG: Measuring inconsistency in meta-analyses. BMJ 2003, 327(7414):557-560.

8. Chen YY, Zhu LP, Li A: Epidemiologic characteristics of dyslipidemia in Jiangxi province adults. Pract Prev Med 2013, 20:234-236.

9. Fu YY, Yu JM, Wang JH: Awareness factors analysis of abonormal blood lipid in Beijing communities. Chin J Pract Intern Med 2010, 1:38-40.

10. Fu YY, Yu JM, Wang JH: Current status of dyslipidemia among overweight and obese population in Beijing community. Chin J Cardiol 2010, 28:562-566.

11. Gao B, Chen F, Zhang YP: Cross-sectional survey of lipid level in adults orth of nof Qinlin in Shanxi. Chin J Arterioscler 2010, 10:824-827.

12. Gao Y, Liu YB, Li ZM: Relationships between lipid level and fat distribution in Jilin rural area middle-aged population. Chin J Gerontol 2013, 33:2107-2109.

13. Guan ZJ, Xia CY: The study of prevention and treatment on the incidence of dyslipidemia of rural population in medical examination in Beijing. Chin Foreign Med Res 2012, 10:63-65.

14. Guo MH, Han XY, Li Z: The survey about prevalent charateristics of common chronic diseases among adults in Beijing Chaoyang district. Chin J Prev Control Chronic Dis 2013, 21:294-296.

15. Hu XL, Xie HB, Xu WH: Dyslipidemia and associated risk factors among residents in the Baimashan Ecological Area of Suichang. Prev Treat Cardi -Cereb Vasc Dis 2012, 12:201-203.

16. Hu XZ, Wang ST, Liu ZS: Correlation of dyslipidemia distribution and chronic kidney disease in Zhengzhou older population. Chin J Gerontol 2011, 31:3584-3586.

17. Jin LZ, Huang RH, Wu WM: Investigation on status of lipid disorders and chronic noninfectious diseases aggregation in Doumen Rural area of Zhuhai city. J Sun Yat Sen Univ (Med Sci) 2009, 30:151-154.

18. Li J: Hypertension on Middle-Elderly City Community Residents in Taishan District of Tai'an City. Tai'an, China: Taishan Medical University; 2010. 
19. Li J, Zhang YJ, Sun YH: Investigation of chronic disease incidence in Beijing Sunhe area residents. Chin J Gen Pract 2011, 9:600-601.

20. Li JH, Wang LM, Li YC, Bi YF, Jiang Y, Mi SQ, Dai M, Xu Y, Ning G, Zhao WH Epidemiologic characteristics of dyslipidemia in Chinese adults 2010. Zhonghua Yu Fang Yi Xue Za Zhi 2012, 46(5):414-418.

21. Li JH, Wang LM, Mi SQ, Zhang M, Li YC, Jiang Y, Xu Y, Dai M, Wang LH: Awareness rate, treatment rate and control rate of dyslipidemia in Chinese adults, 2010. Zhonghua Yu Fang Yi Xue Za Zhi 2012, 46(8):687-691.

22. Li SL, Yu JX, Zhang YL: Epidemiology of dyslipidemia in residents of Yan'an district. S China J Prev Med 2011, 37:17-20.

23. Li XH, Li L, Qiao Y: Epidemiologic analysis of dyslipidemia in adult Tibetan population in Tibet. Chin Circ J 2009, 24:458-460.

24. Li Y, Li WS, Qu WH: Investigation of prevalence rate of dyslipidemia among immigrant population of rural residents in three gorges reservoir area. Chin Med Herald 2012, 9:108-112.

25. Li Y, Zhai L, Wang HB: The status quo of common chronic diseases among adults in Beijing Haidian district. Chin J Prev Control Chronic Dis 2010, 18:261-264.

26. Liang $Y Q$, Zhou $Y Y$, Wu YQ: Epidemiologic survey of dyslipidemia among residents aged $\geq 60$ years in Rong-Gui community and relationship between dyslipidemia and inter-arm blood pressure difference. New Med 2013, 2:97-100.

27. Liao XY, Xu GF, Wu J: Epidemiological study of hyperlipidemia with cardiovascular risk factors in urban and rural communities. West China Med J 2013, 1:14-17.

28. Liu DW, Wan J, Liu ZS, Wang P, Cheng GY, Shi XZ: Association between dyslipidemia and chronic kidney disease: a cross-sectional study in the middle-aged and elderly Chinese population. Chin Med J (Engl) 2013, 126(7):1207-1212.

29. Liu XY, Liu L, Zhao Y: Investigation of dyslipidemia prevalence and risk factors in Yinchuan city adults. J Ningxia Med Univ 2011, 33:27-31.

30. Luo R, Wang YH, Wang XL: Distribution of dyslipidemia among adult residents in Chongqing. J Chongqing Med Univ 2010, 25(7):1086-1088.

31. Luo WP, Liu LX, Ma JP: The analysis about residents chronic disease and risk factors of behavior in Xinjiang monitoring stations in 2010. Bull Dis Control Prev (China) 2013, 28:20-23.

32. Mo JF, Song $\mathrm{XL}$, Xu YJ: The correlation research of dyslipidemia prevalence and risk factors about in Guangdong province adults. S China J Prev Med 2013, 39:11-17.

33. Pang QY, Han B, You A: The Effect Evaluation and Research about Body Mass Index, Waist Circumference and Girth Ratio Predict Dyslipidemia. Changzhi, China: 1st Jinjiluyu Epidemilogy Symposium; 2008.

34. Pang QY, Yu DH, Lu J: Distribution characteristics of dyslipedemia and related-risk factors in Henan rural residents. J Zhengzhou Univ (Med Sci) 2009, 44:547-550.

35. Shao YQ: Epidemiological study on lipid level and its abnormal rate of Wenzhou community population. Mod Pract Med 2011, 23:22-25.

36. Sheng L, Ye P, Xu RY: Dyslipidemia distribution characteristics of Beijing older male residents. Clin Focus 2011, 26:1572-1574.

37. Wang CJ, Li YQ, Li LL, Wang L, Zhao JZ, You AG, Guo YR, Li WJ: Relationship between resting pulse rate and lipid metabolic dysfunctions in Chinese adults living in rural areas. PLoS One 2012, 7(11):e49347.

38. Wang JH, Hu DY, Fu YY: Prevalence of dyslipidemia and borderline dyslipidemia and other risk factors of coronary heart disease in residents from Beijing communities. Chin J Cardilol 2010, 38:175-180.

39. Wu ZF, Wang L, Ma GQ: Relationship between body mass index and blood lipid or blood pressure in Tianjin suburbs senile male cohort. Chin J Prev Control Chronic Non Commun Dis 2009, 17:293-294.

40. Yin L, Li GC, Liu LY: Intervention of main chronic disease and related factors in Hunan province community residents. Pract Prev Med 2011, 18(6):1148-1150

41. You A: The Prevalence and Influencing Factors of Type 2 Diabetes Mellitus in a Rural Population of Henan Province. Zhengzhou, China: Zhengzhou University; 2009

42. Yuan XH: Investigation of the prevalence of hyperlipidaemia in Yunfu city. China Mod Med 2012, 9:176-177.

43. Zhang XW, Ye Z, Zhou D, Zhang J, Wang H, He QF, Fang L, Zhao M, Shu D, Hu R, Gong W: Prevalence of dyslipidemia and its distribution among adults, a cross-sectional study in Zhejiang. Dis Surveill 2012, 27(5):395-399.

44. Zhao YZ, Feng SG, Li GM: The epidemiological study on dyslipidemia in Nanchong community. Med J West China 2012, 24:1948-1950.
45. Zhou WJ, Zhu Y, Liu P: Epidemiology survey of dyslipidemia among residents in Wuxi City and its influence factors. Jiangsu J Prev Med 2012, 23:20-22.

46. Zhao WH, Zhang J, You Y, Man QQ, Li H, Wang CR, Zhai Y, Li Y, Jin SG, Yang $X G$ : Epidemiologic characteristics of dyslipidemia in people aged 18 years and over in China. Zhonghua Yu Fang Yi Xue Za Zhi 2005, 39(5):306-310.

47. Toth PP, Potter D, Ming EE: Prevalence of lipid abnormalities in the United States: the National Health and Nutrition Examination Survey 2003-2006. J Clin Lipidol 2012, 6(4):325-330.

48. Zhou B, Rao X, Dennis BH, Li Y, Zhuo Q, Folsom AR, Yang J, Li Y, Stamler J, Cao T, Guo C, Thomas RP, Zhao L, Liu X, Tian X, Zheng R, for the PRC-USA Cardiovascular and Cardiopulmonary Research Group: The relationship between dietary factors and serum lipids in Chinese urban and rural populations of Beijing and Guangzhou. PRC-USA Cardiovascular and Cardiopulmonary Research Group. Int J Epidemiol 1995, 24(3):528-534.

49. Chen CM: Overview of obesity in Mainland China. Obes Rev 2008, 9(Suppl 1):14-21.

50. Goff DC Jr, Bertoni AG, Kramer H, Bonds D, Blumenthal RS, Tsai MY, Psaty BM: Dyslipidemia prevalence, treatment, and control in the Multi-Ethnic Study of Atherosclerosis (MESA): gender, ethnicity, and coronary artery calcium. Circulation 2006, 113(5):647-656.

51. Taylor HA Jr, Akylbekova EL, Garrison RJ, Sarpong D, Joe J, Walker E, Wyatt SB, Steffes MW: Dyslipidemia and the treatment of lipid disorders in African Americans. Am J Med 2009, 122(5):454-463.

52. Thorlund K, Imberger G, Johnston BC, Walsh M, Awad T, Thabane L, Gluud C, Devereaux PJ, Wetterslev J: Evolution of heterogeneity (I2) estimates and their $95 \%$ confidence intervals in large meta-analyses. PLoS One 2012, 7:e39471.

doi:10.1186/s12963-014-0028-7

Cite this article as: Huang et al:: Epidemiology of dyslipidemia in Chinese adults: meta-analysis of prevalence, awareness, treatment, and control. Population Health Metrics 2014 12:28.

\section{Submit your next manuscript to BioMed Central and take full advantage of:}

- Convenient online submission

- Thorough peer review

- No space constraints or color figure charges

- Immediate publication on acceptance

- Inclusion in PubMed, CAS, Scopus and Google Scholar

- Research which is freely available for redistribution
C BioMed Central 